\title{
Arginine methylation of Aubergine mediates Tudor binding and germ plasm localization
}

\author{
YOHEI KIRINO, ${ }^{1}$ ANASTASSIOS VOUREKAS, ${ }^{1}$ NABIL SAYED, ${ }^{1}$ FLAVIA DE LIMA ALVES, ${ }^{2}$ TRAVIS THOMSON, ${ }^{3}$ \\ PAUL LASKO, ${ }^{3}$ JURI RAPPSILBER, ${ }^{2}$ THOMAS A. JONGENS, ${ }^{4}$ and ZISSIMOS MOURELATOS ${ }^{1}$ \\ ${ }^{1}$ Division of Neuropathology, Department of Pathology and Laboratory Medicine, University of Pennsylvania School of Medicine, \\ Philadelphia, Pennsylvania 19104, USA \\ ${ }^{2}$ Wellcome Trust Centre for Cell Biology, University of Edinburgh, Edinburgh EH8 9YL, United Kingdom \\ ${ }^{3}$ Department of Biology and Developmental Biology Research Initiative, McGill University, Montreal, Quebec H3A 1B1, Canada \\ ${ }^{4}$ Department of Genetics, University of Pennsylvania School of Medicine, Philadelphia, Pennsylvania 19104, USA
}

\begin{abstract}
Piwi proteins such as Drosophila Aubergine (Aub) and mouse Miwi are essential for germline development and for primordial germ cell (PGC) specification. They bind piRNAs and contain symmetrically dimethylated arginines (sDMAs), catalyzed by dPRMT5. PGC specification in Drosophila requires maternal inheritance of cytoplasmic factors, including Aub, dPRMT5, and Tudor (Tud), that are concentrated in the germ plasm at the posterior end of the oocyte. Here we show that Miwi binds to Tdrd6 and Aub binds to Tudor, in an sDMA-dependent manner, demonstrating that binding of sDMA-modified Piwi proteins with Tudor-domain proteins is an evolutionarily conserved interaction in germ cells. We report that in Drosophila tud ${ }^{1}$ mutants, the piRNA pathway is intact and most transposons are not de-repressed. However, the localization of Aub in the germ plasm is severely reduced. These findings indicate that germ plasm assembly requires sDMA modification of Aub by dPRMT5, which, in turn, is required for binding to Tudor. Our study also suggests that the function of the piRNA pathway in PGC specification may be independent of its role in transposon control.
\end{abstract}

Keywords: Argonaute; Aubergine; piRNA; Piwi; Tudor; miRNA

\section{INTRODUCTION}

Ribonucleoprotein complexes composed of Argonaute proteins bound to small RNAs form the essential effector complexes of RNA silencing (Liu et al. 2008). Argonaute proteins contain two characteristic domains termed PAZ and PIWI and are divided into two subclades: Ago and Piwi (Carmell et al. 2002). Ago proteins are typically expressed in most cell types and bind to microRNAs (miRNAs) and short interfering RNAs (siRNAs) (Liu et al. 2008). Piwi family proteins are expressed in the germline and bind to piRNAs that consist of 25-31 nucleotides (nt) (Klattenhoff and Theurkauf 2008; Ghildiyal and Zamore 2009; Kim et al. 2009). The PIWI domain of Ago and Piwi proteins is an RNase $\mathrm{H}$ protein domain that may display endonucleolytic activity toward RNAs that are complementary to bound

Reprint requests to: Zissimos Mourelatos, Division of Neuropathology, Department of Pathology and Laboratory Medicine, University of Pennsylvania School of Medicine, Philadelphia, PA 19104, USA; e-mail: mourelaz@uphs.upenn.edu; fax: (215) 898-9969.

Article published online ahead of print. Article and publication date are at http://www.rnajournal.org/cgi/doi/10.1261/rna.1869710.
miRNAs or piRNAs (Ghildiyal and Zamore 2009; Kim et al. 2009).

Piwi proteins are essential for germline development and germ cell specification. Drosophila melanogaster expresses three Piwi proteins termed Aubergine (Aub) (Harris and Macdonald 2001), Piwi (Cox et al. 1998), and Ago3 (Brennecke et al. 2007; Gunawardane et al. 2007; Li et al. 2009). Mice express three Piwi proteins known as Mili (Kuramochi-Miyagawa et al. 2004), Miwi (KuramochiMiyagawa et al. 2001; Deng and Lin 2002), and Miwi2 (Carmell et al. 2007; Girard and Hannon 2008). The sequence diversity of piRNAs is immense, and hundreds of thousands of unique piRNAs have been described in diverse species (Aravin et al. 2003, 2006; Girard et al. 2006; Grivna et al. 2006; Lau et al. 2006; Ruby et al. 2006; Saito et al. 2006; Vagin et al. 2006; Watanabe et al. 2006; Brennecke et al. 2007; Houwing et al. 2007; Kirino et al. 2009). piRNAs originate from piRNA clusters but also from many other genomic areas, including intergenic and genic regions. Many piRNAs are derived from transposable and repetitive elements and also target transposons (Malone and Hannon 2009). However, large classes of piRNAs in different 
species (for example, pachytene piRNAs [Girard et al. 2006] in mice or $21 \mathrm{U}$ piRNAs in Caenorhabditis elegans [Ruby et al. 2006]) do not appear to be derived from or to target transposons, and their targets and functions remain unknown.

Arginine methylation is an important post-translational modification that is catalyzed by protein methyltransferases (PRMTs) and occurs either as asymmetric arginine dimethylation (aDMA) or symmetric arginine dimethylation (sDMA) (Krause et al. 2007). PRMT5 and its cofactor MEP50/WD45 form the methylosome (Friesen et al. 2001, 2002; Meister et al. 2001) and deposit sDMAs in diverse proteins, such as the $\mathrm{Sm}$ proteins, components of small nuclear ribonucleoproteins (snRNPs) (Friesen et al. 2001, 2002; Meister et al. 2001), and histones (Zhao et al. 2009). Methylated arginines, and in particular sDMAs, bind to Tudor domains and regulate protein-protein interactions (Bedford and Richard 2005; Cote and Richard 2005). For example, sDMA modification of $\mathrm{Sm}$ proteins promotes their binding to the Tudor domain of the survival of motor neurons (SMN) protein (Selenko et al. 2001), and this interaction facilitates snRNP assembly in mammals (Friesen et al. 2001; Meister et al. 2001; Boisvert et al. 2002; Gonsalvez et al. 2007).

Specification of primordial germ cells (PGCs) in the developing Drosophila embryo requires maternal inheritance of cytoplasmic factors that are concentrated in the posterior pole in an area known as the pole or germ plasm (Ephrussi and Lehmann 1992; Jongens et al. 1992; Williamson and Lehmann 1996; Houston and King 2000; Mahowald 2001; Strome and Lehmann 2007; Bastock and St Johnston 2008; Dansereau and Lasko 2008). Pole plasm contains electron-dense granules and related amorphous material that is rich in ribonucleoproteins and mitochondria; it is related to nuage, which surrounds the nurse cell nuclei and contains some of the same components (Dansereau and Lasko 2008; Chuma et al. 2009). Similar electron-dense amorphous material often in close apposition to mitochondria is found in the cytoplasm of germ cells in various species and is known as $\mathrm{P}$ granules in $C$. elegans, germinal granules in Xenopus, and intermitochondrial cement and chromatoid bodies in mice (Dansereau and Lasko 2008; Chuma et al. 2009). A set of maternally expressed genes (often referred to as posterior group or grandchildless genes) are required for PGC specification (Schupbach and Wieschaus 1986), and invariably the protein or RNA products of these genes are concentrated in the pole plasm and are incorporated in PGCs (Ephrussi and Lehmann 1992; Williamson and Lehmann 1996; Houston and King 2000; Mahowald 2001; Strome and Lehmann 2007; Bastock and St Johnston 2008; Dansereau and Lasko 2008). Loss-of-function mutations of grandchildless genes lead to offspring that do not form PGCs and are thus sterile (Williamson and Lehmann 1996; Houston and King 2000; Mahowald 2001; Strome and Lehmann 2007; Bastock and St Johnston 2008; Dansereau and Lasko 2008).
Among these genes are $a u b$, which encodes the piRNAbinding protein Aub (Harris and Macdonald 2001; Brennecke et al. 2007; Gunawardane et al. 2007); csul/dart5, the Drosophila homolog of PRMT5 (dPRMT5) (Gonsalvez et al. 2006; Anne et al. 2007); valois, the Drosophila homolog of MEP50 (dMEP50) (Anne and Mechler 2005; Cavey et al. 2005); and tudor (Boswell and Mahowald 1985; Thomson and Lasko 2004, 2005; Arkov et al. 2006). In valois-null mutants, dPRMT5 is destabilized, resulting in a loss of sDMA modifications of target proteins, indicating that dMEP50 is required for sDMA production in concert with dPRMT5 (Gonsalvez et al. 2006). Piwi family proteins, including Aub, from diverse species, contain sDMAs, and the sDMAs in Drosophila are catalyzed by dPRMT5 (Kirino et al. 2009). These findings explain the genetic relationship between aub, csul, and valois by demonstrating that Csul/ dPRTM5 (and presumably its Valois/dMEP50 cofactor) methylate Aub (Kirino et al. 2009).

Tudor is an $\sim 285-\mathrm{kDa}$ protein that contains 11 Tudor domains (Boswell and Mahowald 1985; Thomson and Lasko 2004, 2005; Arkov et al. 2006). Tudor domains of other proteins have been shown to bind to methylated amino acids and specifically to sDMAs, suggesting that an important function of Tudor domains is to bind to sDMAcontaining proteins (Selenko et al. 2001; Bedford and Richard 2005; Cote and Richard 2005). In mice, several Tudor-domain-containing proteins (Tdrd1, Tdrd4, Tdrd5, Tdrd6, and Tdrd7) are expressed in the germline (Smith et al. 2004; Hosokawa et al. 2007). Genetic disruption of $T d r d 1$ leads to arrest in spermatogenesis and male sterility (Chuma et al. 2006). In Tdrd1-null spermatocytes, there is a strong reduction of the intermitochondrial cement, but the chromatoid body shows a milder disruption of its architecture (Chuma et al. 2006). Tdrd 1 contains four Tudor domains and associates with Mili (Reuter et al. 2009; Vagin et al. 2009; Wang et al. 2009). It was recently shown that sDMA modifications in Mili are required for binding to $\operatorname{Tdrd} 1$, and in the absence of Tdrd1, there is up-regulation of L1 retrotransposons (Reuter et al. 2009; Vagin et al. 2009). Tdrd6 is the mouse homolog of Drosophila Tudor; it contains seven Tudor domains and associates predominantly with Miwi (Vagin et al. 2009; Vasileva et al. 2009), and also with Mili (Vagin et al. 2009; Vasileva et al. 2009). Interestingly, in Tdrd6-null mice, the architecture of the chromatoid body is severely disrupted (Vasileva et al. 2009). In contrast to the transposon up-regulation that is seen in Tdrd1-null mice, Tdrd6-null mice do not show any de-repression of transposons (Vasileva et al. 2009), and the piRNA profile of Tdrd6-null spermatocytes is not altered (Vagin et al. 2009).

Here we demonstrate that Aub binds to Tudor and that the sDMAs of Aub are essential for this binding. We also show that Miwi binds to Tdrd6 and sDMAs of Miwi mediate Tudor binding in vitro. Thus, the binding of sDMA-modified Piwi family proteins with Tudor-domain-containing proteins is an evolutionarily conserved interaction in germ cells. 
Furthermore, we report that in Drosophila tud ${ }^{1}$ mutants, neither the levels of Piwi proteins nor of piRNAs are affected in the female germline. However, the localization of Aub in the pole plasm is severely reduced. These findings indicate that pole plasm assembly requires arginine methylation of Aub by dPRMT5, which, in turn, is required for binding to Tudor. The finding that loss of Tudor results in only very mild transposon de-repression suggests that the function of the piRNA pathway in PGC specification may be independent of its function in transposon control.

\section{RESULTS}

We have previously shown the presence of symmetrically dimethylated arginines (sDMAs) in the amino termini of Piwi proteins from diverse species, including Drosophila Aubergine (Aub) and mouse Miwi, and we hypothesized that sDMAs might mediate interaction with Tudordomain-containing proteins. To identify proteins that bind specifically to sDMAs of Aub and Miwi, we performed binding experiments using biotinylated peptides derived from the amino termini of Aub and Miwi that contain sDMAs (Fig. 1A). As controls, we used peptides with the
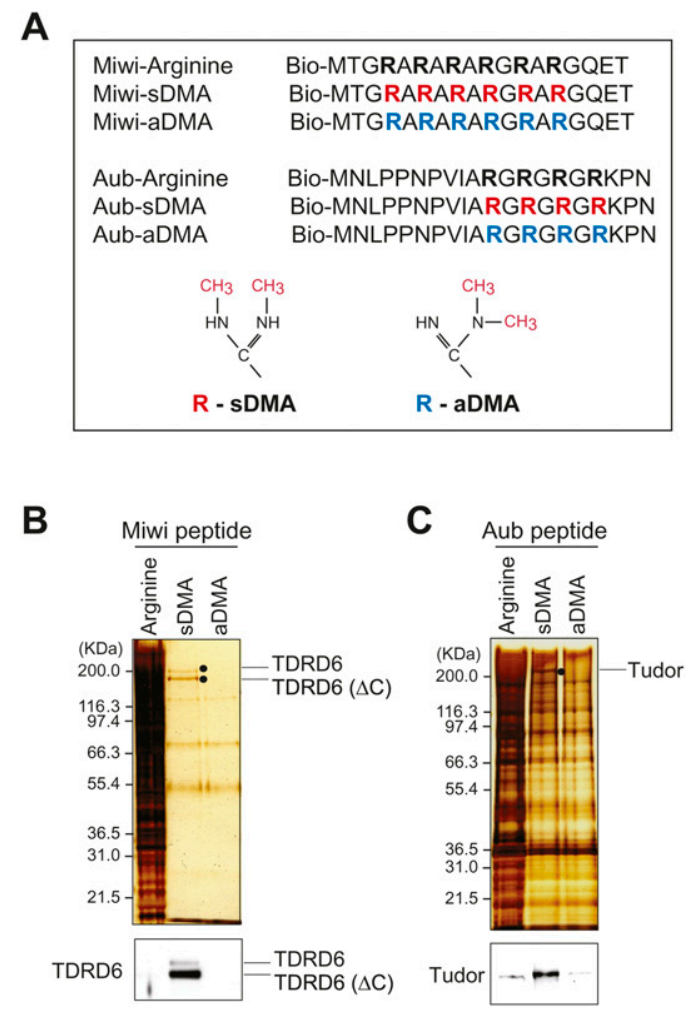

FIGURE 1. Drosophila Tudor protein and its mouse homolog, Tdrd6, bind specifically to sDMAs of peptides derived from Aub and Miwi proteins, respectively. (A) Biotinylated peptides used for pull-downs. (B) Mouse testis or $(C)$ Drosophila ovary lysates were incubated with indicated peptides; bound proteins were visualized by silver staining and identified by mass spectrometry. Western blots of indicated proteins from pull-downs are shown. same sequence but containing either unmodified arginines or arginines containing asymmetrical dimethyl groups (aDMAs) (Fig. 1A). We immobilized equal amounts of each biotinylated peptide on streptavidin-Sepharose and then incubated the Miwi peptides with mouse testis lysates and the Aub peptides with Drosophila ovary lysates. After extensive washes, we analyzed bound proteins with NuPAGE and silver staining. As shown in Figure 1B, Miwi peptide containing unmodified arginines bound numerous proteins. In contrast, very few proteins bound to sDMA or aDMA Miwi peptides (Fig. 1B). Two prominent bands at $\sim 200 \mathrm{kDa}$ were specifically bound to the sDMA-Miwi peptide (Fig. 1B), and they were identified as Tdrd6 by mass spectrometry (see Supplemental Table). The upper band corresponded to full-length Tdrd6, and the lower band corresponded to a naturally found C-terminally truncated form of Tdrd6 (known as $\Delta \mathrm{C}$-Tdrd6) (Vasileva et al. 2009). To confirm the results of the mass spectrometry analysis, we performed Western blotting on the eluates of the Miwi peptides, and we detected Tdrd6 and $\Delta \mathrm{C}$-Tdrd6 only in the eluates of sDMA-Miwi peptides (Fig. 1B).

We performed a similar experiment and analysis with Aub peptides. As shown in Figure 1C, a $>200-k D a$ protein band was specifically seen in eluates from sDMA-Aub and was identified by mass spectrometry as Drosophila Tudor protein (Supplemental Table). Although the calculated molecular weight of Tudor is $\sim 285 \mathrm{kDa}$, its mobility is faster in NuPAGE. Western blot analysis of the eluates with anti-Tudor antibody confirmed the presence of Tudor in sDMA-Aub eluates. These findings show that Drosophila Tudor protein binds specifically to sDMA-Aub, and Tdrd6, the mouse homolog of Tudor, binds to sDMA-Miwi. It is interesting to note that numerous proteins bind to Aub and Miwi peptides with unmodified arginines, while far fewer proteins bind to aDMA-, or sDMA-modified Aub and Miwi peptides, and only Tudor or Tdrd6 binds specifically to sDMA-Aub and sDMA-Miwi, respectively.

We next performed immunoprecipitations using an antibody against Tdrd6 or non-immune rabbit serum (NRS, negative control) from mouse testis, and we probed the immunoprecipitates with Tdrd6 and Miwi antibodies. The properties of our anti-Miwi antibody are shown in Figure 2A. As shown in Figure 2B, Miwi was present in Tdrd6 immunoprecipitates, consistent with recent reports of Miwi-Tdrd6 interaction (Vagin et al. 2009; Vasileva et al. 2009). We also performed immunoprecipitations using anti-Tudor or NRS from wild-type (wt) and dPRMT5/ csul-null Drosophila ovary lysates, and we probed the immunoprecipitates with anti-Tudor or anti-Aub antibodies. csul-null flies cannot produce symmetrical methylation on arginines, and we have previously shown that Aub does not contain sDMAs in ovaries of csul-null flies. As shown in Figure 2C, Aub was found in the antiTudor immunoprecipitates from wild-type (wt) but not 
A

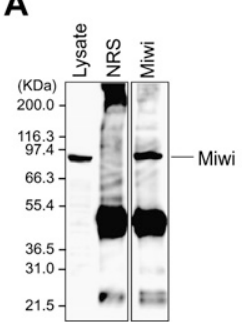

B

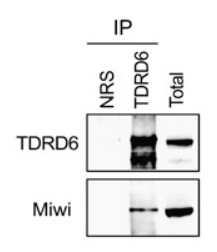

C

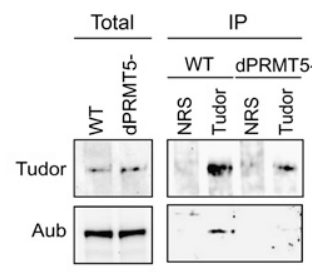

FIGURE 2. Miwi interacts with Tdrd6 in vivo, and sDMAs of Aub are required for Tudor binding in vivo. $(A)$ Properties of anti-Miwi antibody. Mouse testis cell lysate and immunoprecipitates (IP) using anti-Miwi or non-immune rabbit serum (NRS, negative control) were probed with anti-Miwi antbody. (B) Tdrd6 or NRS immunoprecipitates from mouse testis were probed with indicated antibodies; total lysates prior to immunoprecipitation are shown. (C) Tudor or NRS immunoprecipitates from wild-type (wt) and dPRMT5-null ovaries were probed with indicated antibodies.

from csul-null ovaries, indicating that sDMA modifications of Aub are essential for Tudor interaction in vivo.

To investigate the Aub-Tudor interaction further, we performed in vitro binding experiments. We have previously shown that in Aub, the four arginines that are substrates for symmetrical dimethylation are found in tandem very close to the N-terminus (Fig. 3A, Aub-WT) and mutation of these arginines into lysines abolishes sDMAs in Aub (Fig. 3A, Aub-4K). We immunopurified Flag-tagged Aub-WT or mutant Aub-4K expressed stably in Drosophila S2 cells (which express dPRMT5), and equivalent amounts (Fig. 3B, bottom panel) were used in binding experiments with in vitro translated and radiolabeled Tudor protein. As shown in Figure 3B (upper panel), Tudor bound to AubWT but not Aub- $4 \mathrm{~K}$, indicating that Aub protein interacts with Tudor and that the four arginines that can be modified to sDMAs are required for this interaction.

Previous work has shown that a deletion mutant of Tudor termed Tud- $\Delta 3$, expressing Tudor domains 1 and domains $7-11$, rescues germ cell formation in a strong loss of function $t u d^{1}$ mutant background (Fig. 3C). In contrast, deletion mutants of Tudor domains 7-11 (Fig. 3C,Tud- $\Delta 1$ ) and deletion of domains 1-9 (Fig. 3C,Tud- $\Delta 2$ ) were unable to rescue germ cell formation in strong loss-of-function tud alleles, indicating that domains 7-11 of Tudor are critical for germ cell formation (Arkov et al. 2006). We tested the ability of these deletion mutants to interact with Aub protein using in vitro binding experiments. As shown in Figure $3 \mathrm{D}$, Tud- $\Delta 3$ but not Tud- $\Delta 2$ bound specifically to Aub-WT. We observed a strong, nonspecific binding of Tud- $\Delta 1$ to the beads (that we did not observe with fulllength Tudor) (Fig. 3B), suggesting that the protein produced from the Tud- $\Delta 1$ construct might be misfolded and prone to nonspecific binding. Overall, these binding experiments suggest that Tudor domains 7-11, which are required for germ cell formation in vivo, interact with Aub.

Next, we analyzed Piwi proteins and the piRNA pathway in $t d^{1}$ mutant ovaries. $t u d^{1}$ is a strong loss-of-function mutant allele (K1036UAG) that encodes a prematurely truncated form of Tudor that is not detectable in immunoblots (Fig. 4A; Arkov et al. 2006). However, the levels of all three Drosophila Piwi proteins (Piwi, Aub, and Ago3) and of the miRNA-binding Agol protein were the same between wildtype and $t u d^{1}$ ovaries. Similar amounts of Aub and Piwi proteins were immunoprecipitated between wild-type and $t_{u} d^{1}$ ovaries (Fig. 4B), and the amount of bound piRNAs was the same between wild-type and $t u d^{1}$ ovaries (Fig. 4C). We have previously reported a reduction of Aub and Ago3 protein levels in csul ovaries (Kirino et al. 2009). We have found that there is variability in the levels of Aub in csul ovaries that may correlate with culture conditions. It is also possible that loss of dPRMT5 may affect an as-yet-unidentified factor(s) that leads to reduction of Aub protein levels.

We also tested the levels of several transposon transcripts, whose expression is sensitive to mutations that disrupt piRNA-mediated transposon silencing (Vagin et al. 2006; Li et al. 2009) in csul (dPTMT5-null) and tud ${ }^{1}$ ovaries. As shown in Figure 4D, transcript levels of Diver, $H e T-A, A c c o r d 2$, and Blood were clearly up-regulated in csul ovaries. However, in $t u d^{1}$ ovaries, only the Blood retrotransposon was up-regulated. Next, we analyzed by confocal microscopy the localization of Aub in wild-type and $t u d^{1}$ ovaries. As shown in Figure 4E, the levels and localization of Aub were the same between wild-type and $t u d^{1}$ early egg chambers. However, there was a marked reduction of Aub that is localized in the pole plasm in $t u d^{1}$ ovaries (Fig. 4F). Collectively, these findings indicate that in the absence of Tudor, neither the levels of Piwi proteins nor piRNAs are affected in the female germline, and silencing of most transposons is intact. However, the localization of Aub in the pole plasm is severely affected.

\section{DISCUSSION}

We have recently shown that dPRMT5 (Csul/dart5) catalyzes sDMA modifications of Aub (Kirino et al. 2009). We predict that a similar requirement for dMEP50/Valois in Aub methylation is required since dPRMT5 stability and function require dMEP50. In this study, we identify that an important and evolutionarily conserved function of sDMA modifications of Piwi family proteins is to direct their binding to Tudor-containing proteins. One such interaction is between sDMA-modified Aub and Tudor in Drosophila oocytes. Collectively these findings provide an explanation for the relationship between the protein products of four posterior-group genes that has been previously elusive: dPRMT5 and dMEP50 produce sDMAs in Aub, which, in turn, are required for binding to Tudor (Fig. 5).

A general role of Tudor-domain-containing proteins and Piwi family proteins in germline development is now 
A 1
Aub-WT MNLPPNPVIARGRGRGRKPNNVEANRGFAP
Aub-4K MNLPPNPVIAKGKGKGKKPNNVEANRGFAP

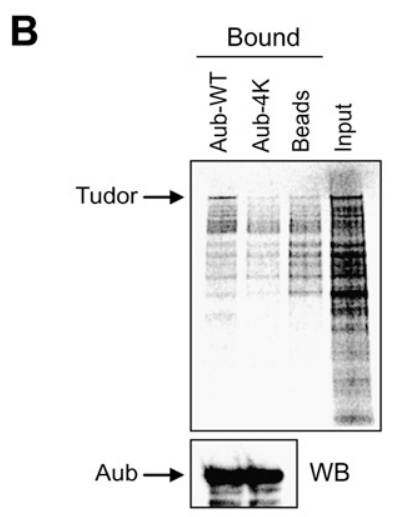

E

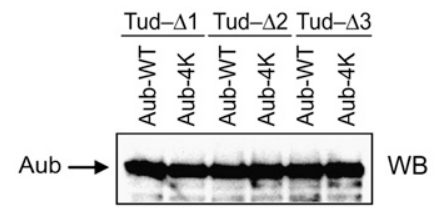

C
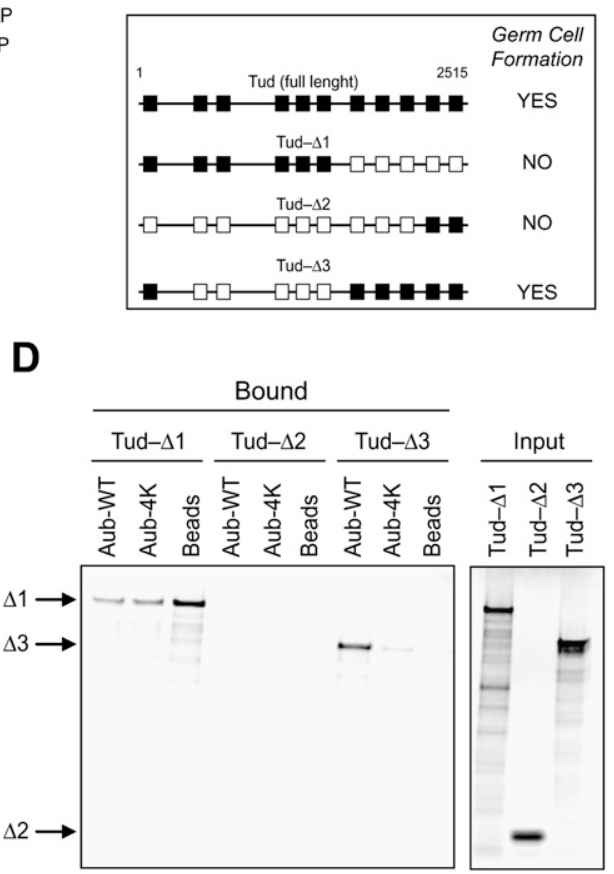

FIGURE 3. sDMAs of Aub are required for binding to Tudor in vitro. (A) Sequences of AubWT and mutant Aub-4K, showing the four arginines that are substrates for methylation and that were substituted for lysines. (B) In vitro translated and radiolabeled full-length Tudor was incubated with immunopurified Flag-tagged wild-type Aub (wt) or mutant Aub (Aub-4K, not containing sDMAs) produced is S2 cells, or with Flag-beads only. Bound proteins were analyzed by NuPAGE and visualized by autoradiography. Input shows $10 \%$ of in vitro translated Tudor. Amounts of Aub-wt and Aub-4K were analyzed by Western blot using Flag antibody. $(C)$ Schematic of domain architecture and deletion mutants of Tudor; (boxes) individual Tudor domains; (white boxes) deleted domains. Ability to support germ cell formation is indicated (Arkov et al. 2006). (D) In vitro translated and radiolabeled deletion mutants of Tudor were incubated with immunopurified Aub-wt or Aub-4K, or with Flagbeads only. Bound proteins were analyzed by NuPAGE and visualized by autoradiography. Input shows $10 \%$ of in vitro translated Tudor deletion mutants. (E) Amounts of Aub-wt and Aub- $4 \mathrm{~K}$ of each binding reaction were analyzed by Western blot using Flag antibody.

becoming apparent. Mouse Tdrd1 binds to Mili (Reuter et al. 2009; Wang et al. 2009), and this interaction is dependent on sDMA modifications of Mili (Reuter et al. 2009; Vagin et al. 2009). Although the levels of Mili protein and bound piRNAs are not changed in Tdrd1-null spermatocytes (Reuter et al. 2009; Wang et al. 2009), the identity of the Mili-bound piRNAs is altered with overrepresentation of genic piRNAs at the expense of transposon-derived piRNAs (Reuter et al. 2009). This shift correlates with L1 transposon de-repression (Reuter et al. 2009; Vagin et al. 2009) and DNA demethylation (Reuter et al. 2009), which is similar to the phenotype observed in mili-null spermatocytes (Aravin et al. 2007). Furthermore, in the absence of Tdrd1 or Mili, Miwi2, which is normally a nuclear protein, delocalizes to the cytoplasm (Reuter et al. 2009; Vagin et al. 2009), and in the absence of Mili, the cytoplasmic Miwi2 is devoid of piRNAs (Aravin et al. 2007). Miwi2 also associates with Tdrd1 (Vagin et al. 2009). These findings indicate that the function of Tdrd 1 is closely related to Mili and Miwi2, and Tdrd1 has an important role in specifying the piRNA content of Mili (Reuter et al. 2009) and the operation of the pingpong cycle of piRNA amplification (Vagin et al. 2009).

Mouse Tdrd6 interacts with Miwi and Mili (Vagin et al. 2009; Vasileva et al. 2009), and we show in this study that Tdrd6 binds to sDMA-modified peptide of Miwi. In contrast to the Tdrd1-null mice, transposons are not de-repressed in Tdrd6-null spermatocytes (Vasileva et al. 2009), and the piRNA profile of Tdrd6-null spermatocytes is not altered (Vagin et al. 2009). This is consistent with our finding that most transposons are not up-regulated in $t u d^{1}$ Drosophila ovaries, with the exception of the Blood transposon. This may indicate that Tudor is required directly or indirectly for the biogenesis or function of a subset of piRNAs that may target Blood. Future deep sequencing studies of $t u d^{l}$ piRNAs will be required to address whether Blood derepression correlates with loss of cognate piRNAs. However, we note that the relationship between transposon derepression and loss of piRNAs is complex and not well understood. For example, despite widespread changes in the content and levels of piRNAs in $A u b$-null and Ago3-null ovaries, there is only partial overlap between the altered piRNAs and the de-repressed transposons ( $\mathrm{Li}$ et al. 2009; Malone et al. 2009). It is also possible that piRNAs and piRNA-associated proteins target and regulate the expression of mRNAs whose protein products are important for the specification of germ cells. For example, the Drosophila AT-chX-1 and AT-chX-2 piRNAs are antisense to Vasa mRNA and down-regulate the expression of Vasa protein, which is essential for germ cell specification (Nishida et al. 2007; Li et al. 2009). An important goal of future studies will be to identify RNAs that are bound by piRNPs in the germ plasm.

It appears that specific members of the Piwi family of proteins function together with Tudor-domain-containing proteins. In that regard, Ago3 and Piwi will likely interact with specific Tudor-domain-containing proteins. It is interesting to note that Spindle E contains a Tudor domain along with an RNA helicase domain and is an important factor for piRNA biogenesis in Drosophila (Savitsky et al. 2006; Vagin et al. 2006; Malone et al. 2009). The mouse homolog of Spindle E is Tdrd9 and shows weak association 
A

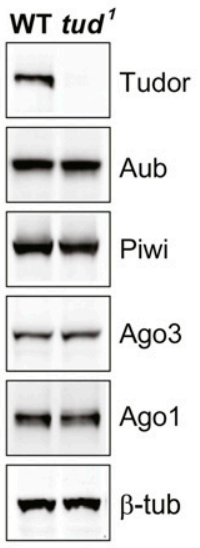

D

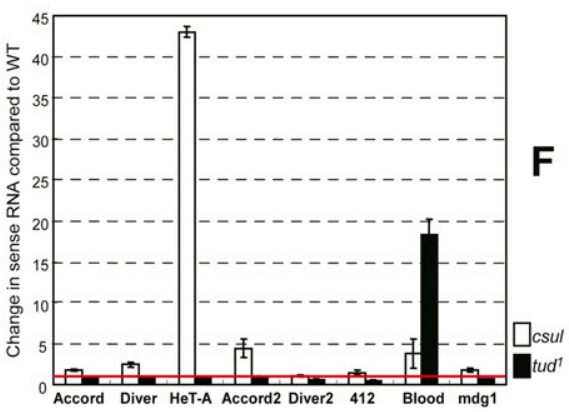

$\mathbf{F}$

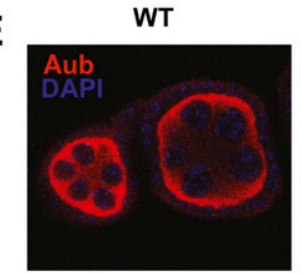

WT

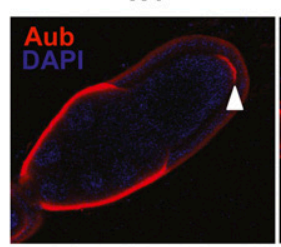

C
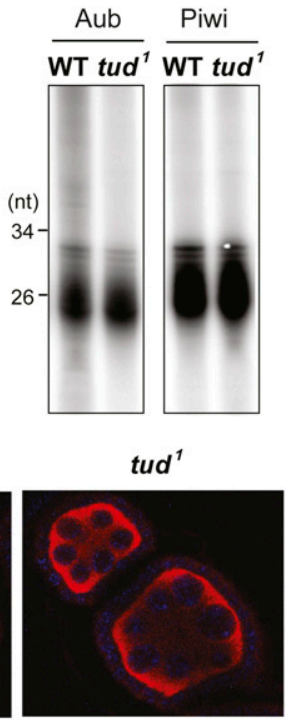

tud $^{1}$

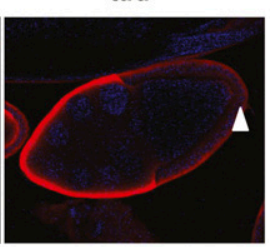

FIGURE 4. Tudor is essential for localization of Aub to the pole plasm but does not affect the levels of Piwi proteins or piRNAs or of most transposon transcripts. $(A)$ Western blots of Drosophila ovary lysates from wild-type (WT) or tudor $\left(t u d^{l}\right)$ with indicated antibodies. $(B)$ Aub or Piwi immunoprecipitates from ovary lysates were probed with Aub and Piwi antibodies, and $(C)$ bound piRNAs were $5^{\prime}$-end-radiolabeled and analyzed by UREA-PAGE. (D) Levels of indicated transposon transcripts in ovaries of wild-type, $t u d^{1}$, and csul/dPRMT5null were examined by qRT-PCR. (Red line) Transcript levels from wild-type ovaries were set as 1, and fold-changes are indicated; averages of three independent experiments with SD values are shown. Localization of Aub in wt and $t u d^{l}$ ovaries in $(E)$ early or $(F)$ late egg chambers; (arrow) pole (germ) plasm.

with Miwi and Miwi2 (Vagin et al. 2009). Krimper, which is also required for piRNA biogenesis in Drosophila, contains a Tudor domain (Lim and Kai 2007). Interactions between these proteins and Piwi family proteins will be interesting to elucidate. At the same time, the occurrence of multiple Tudor domains in Tudor and other Tdrd's suggests that they may form landing pads for additional DMA-containing or other proteins. It is likely that Tudor has multiple binding partners. The functions of Tudor with regard to germ cell specification and posterior patterning appear to involve different regions of the protein (Arkov et al. 2006), and ME31B, eIF4A, Aub, and TER94 have been identified as components of $\mathrm{Tu}-$ dor complexes (Thomson et al. 2008), although direct binding to Tudor has not been demonstrated for any of these proteins other than Aub. Further analysis of Tudorbinding proteins will be important to future studies of germ cell specification and will shed additional light on its function.

\section{MATERIALS AND METHODS}

Analysis of the proteins interacting with peptides containing arginine methylations

Miwi and Aub peptides (Fig. 1A) were synthesized by Millipore. Each peptide was immobilized on Streptavidin Sepharose High Performance (GE Healthcare) and incubated in the lysate produced from mouse testis (Pel-Freez Biologicals) (Miwi peptide) or Drosophila ovary lysate (Aub peptide) for $1.5 \mathrm{~h}$ at $4^{\circ} \mathrm{C}$ in a lysis buffer $(20 \mathrm{mM}$ TrisHCL at $\mathrm{pH} 7.5,200 \mathrm{mM} \mathrm{NaCl}, 2.5 \mathrm{mM}$ $\mathrm{MgCl}_{2}, 0.5 \% \mathrm{NP}-40$, and $0.1 \%$ Triton X-100 in the case of Miwi peptides and complete EDTA-free protease inhibitors [Roche]; and the same buffer but containing $150 \mathrm{mM}$ $\mathrm{NaCl}$ in the case of Aub peptides). After extensive washings, bound proteins were resolved by NuPAGE and visualized by silver staining.

\section{Western blots and immunoprecipitations}

Western blots and immunoprecipitations were performed as described (Kirino et al. 2009). Anti-Mili (17.8) (Kirino et al. 2009), anti-Flag M2 (Sigma), and anti- $\beta$-tubulin (E7; Developmental Studies Hybridoma Bank) were used in this study. Antibodies against the Drosophila Ago1, Aub, Piwi, and Ago3 were gifts from M.C. Siomi and H. Siomi (Keio University) (Miyoshi et al. 2005; Saito et al. 2006; Gunawardane et al. 2007). Drosophila Tudor antibody was described by Thomson et al. (2008). Anti-Tdrd6 antibodies were gifts from R. Jessberger (Mount Sinai School of Medicine) (Vasileva et al. 2009), and S. Chuma (Kyoto University) (Chuma et al. 2006). Anti-Miwi antibody was prepared by immunizing rabbits with a synthetic peptide coupled to KLH (C-ERGGRRRDFHD; Genscript); sera were affinity-purified over a column containing immobilized peptide.

\section{In vitro binding experiments}

Drosophila full-length Tudor and mini-tud constructs $\Delta 1, \Delta 2$, and $\Delta 3$ carrying an $\mathrm{HA}$ epitope at the $\mathrm{N}$ terminus cloned into

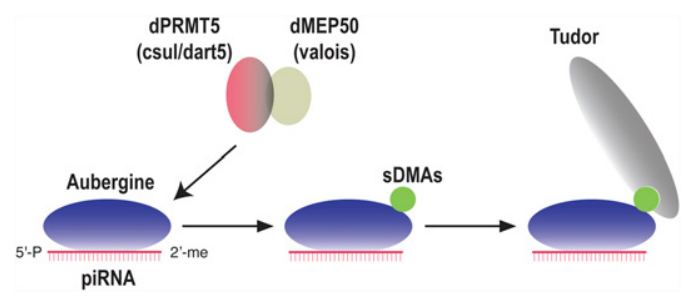

FIGURE 5. Model depicting interactions of indicated proteins in pole (germ) plasm formation. 
$\mathrm{pP}\{\mathrm{CaSpeR}-2\}$ (gifts from A. Arkov, Murray State University) (Arkov et al. 2006) were used as templates for the amplification of the four coding sequences (CDS) by PCR with Pfu Turbo polymerase (Stratagene), following the manufacturer's instructions. PCR primers were:

Forward: 5'-CTCGAGACCATGTACCCGTACGATGTGC-3'; and Reverse: 5'-TCACTGACATTCCTGAAGCT-3'.

After the addition of $3^{\prime}$ adenosine overhangs by incubation with Taq DNA polymerase and dATP, the CDS were cloned into pCRXL-TOPO vector (Invitrogen). Recombinant plasmids were selected for same-strand orientation of CDS with vector T7 RNA polymerase promoter by restriction analysis and were verified by DNA Sequencing. One microgram of recombinant plasmid from each construct, linearized $\sim 100$ bases downstream from the stop codon, was used for in vitro translation using TNT reticulocyte lysate system in the presence of $40 \mu \mathrm{Ci}$ of ${ }^{35} \mathrm{~S}$-methionine in a $50 \mu \mathrm{L}$ reaction for $2 \mathrm{~h}$ at $30^{\circ} \mathrm{C}$. Recombinant wild-type and mutant Flag-Aub were produced in S2 cells and immunoprecipitated using M2 anti-Flag agarose as previously described (Kirino et al. 2009). Fifteen microliters of either wild-type or mutant Aubbound beads were incubated for $1 \mathrm{~h}$ with $15 \mu \mathrm{L}$ of reticulocyte reaction containing ${ }^{35} \mathrm{~S}$-labeled Tudor in RSB-150 buffer $(20 \mathrm{mM}$ Tris- $\mathrm{HCl}$ at $\mathrm{pH} 7.5,150 \mathrm{mM} \mathrm{NaCl}, 5 \%$ glycerol, $2.5 \mathrm{mM} \mathrm{MgCl}_{2}$, $0.05 \% \mathrm{NP}-40$ ) at $4^{\circ} \mathrm{C}$ and washed three times with the same buffer. Proteins bound on the beads were analyzed on NuPAGE $3 \%-8 \%$ Tris-Acetate gels.

\section{Drosophila stocks}

Tudor mutant flies (yw; tud 1 /CyO) were a gift from A. Arkov (Murray State University) (Arkov et al. 2006).

\section{$R N A$ isolation and labeling, and quantitative} $R T-P C R$ analysis

RNA isolation from Drosophila ovaries or immunoprecipitates, 5 '-end labeling of piRNAs, and quantification of the transposon transcript by quantitative RT-PCR were performed as previously described (Kirino et al. 2009). The following primer pairs as described by Li et al. (2009) were used for quantitative RT-PCR:

Accord: forward (5'-ACAATCCACCAACAGCAACA-3') and reverse (5'-AAAAGCCAAAATGTCGGTTG-3');

Diver: forward (5'-GGCACCACATAGACACATCG-3') and reverse (5'-GTGGTTTGCATAGCCAGGAT-3');

$H e T-A$ : forward (5'-CGCGCGGAACCCATCTTCAGA-3') and reverse (5'-CGCCGCAGTCGTTTGGTGAGT-3');

Accord2: forward (5'-TTGCTTTCGGACTTCGTCTT-3') and reverse (5' -TTCCACAACGAAAACAACCA-3');

Diver2: forward (5'-CTTCAGCCAGCAAGGAAAAC-3') and reverse (5'-CTGGCAGTCGGGTGTAATTT-3');

412: forward (5'-CACCGGTTTGGTCGAAAG-3') and reverse (5'-GGACATGCCTGGTATTTTGG-3');

Blood: forward (5'-TGCCACAGTACCTGATTTCG-3') and reverse (5'-GATTCGCCTTTTACGTTTGC-3');

$m d g 1$ : forward ( $5^{\prime}$-AACAGAAACGCCAGCAACAGC-3') and reverse (5'-CGTTCCCATGTCCGTTGTGAT-3'); and

Rp49 (used as a control): forward (5'-CCGCTTCAAGGGACAGT ATCTG-3') and reverse (5'-ATCTCGCCGCAGTAAACGC-3').

\section{Immunofluorescence and confocal microscopy}

Drosophila ovaries were dissected from adult flies and immunostained under standard procedures using anti-Aub (Gunawardane et al. 2007) as the primary antibody and Alexa 594-conjugated anti-mouse IgG (Molecular Probe) as the secondary antibody. All images (Fig. 4) were acquired with a Zeiss LSM 510META NLO confocal microscope with the following specifications, settings, and magnification: for early-stage egg chambers (Fig. 4E), Wavelength: Red $=543 \mathrm{~nm}(100 \%$ transmission $)$, Blue $(\mathrm{DAPI})=740$ $\mathrm{nm}$ (2.5\% transmission), Objectives: Plan-Apochromat 63X/1.4, Scan Zoom: 1.0, Stack size: $\mathrm{X}=142.86 \mu \mathrm{m}, \mathrm{Y}=142.86 \mu \mathrm{m}$, Pinhole: $118 \mu \mathrm{m}$ for Red, $1000 \mu \mathrm{m}$ for DAPI, and for later stage (Fig. 4F), Wavelength: Red $=543 \mathrm{~nm}$ (100\% transmission), Blue $($ DAPI $)=740 \mathrm{~nm}$ (1.5\% transmission), Objectives: Plan-Apochromat 20X/0.8, Scan Zoom: 1.0, Stack size: $\mathrm{X}=450.00 \mu \mathrm{m}, \mathrm{Y}=$ $450.00 \mu \mathrm{m}$, Pinhole: $120 \mu \mathrm{m}$ for Red, $832 \mu \mathrm{m}$ for DAPI.

\section{SUPPLEMENTAL MATERIAL}

Supplemental material can be found at http://www.rnajournal.org.

\section{ACKNOWLEDGMENTS}

We are grateful to A. Arkov (Murray State University) for $t u d^{1}$ flies and Tudor cDNA constructs; to M.C. Siomi and H. Siomi (Keio University) for Aub and Piwi antibodies and Aub cDNA construct; to S. Chuma (Kyoto University) and R. Jessberger (Mount Sinai School of Medicine) for Tdrd6 antibodies; to S. Kuramochi-Miyagawa and T. Nakano for Miwi and Mili cDNA constructs; to R. Beerman for help with fly methodology; and to members of the Mourelatos laboratory for discussions. This work was supported by a Human Frontier Science Program Long Term Fellowship to Y.K.; and GM0720777, NS056070, UL1RR024134, and in part by ITMAT-PENN and SOM-PENN grants to Z.M.; and by HD036631 to P.L.

Received August 6, 2009; accepted October 5, 2009.

\section{REFERENCES}

Anne J, Mechler BM. 2005. Valois, a component of the nuage and pole plasm, is involved in assembly of these structures, and binds to Tudor and the methyltransferase Capsuleen. Development 132: 2167-2177.

Anne J, Ollo R, Ephrussi A, Mechler BM. 2007. Arginine methyltransferase Capsuleen is essential for methylation of spliceosomal Sm proteins and germ cell formation in Drosophila. Development 134: $137-146$.

Aravin AA, Lagos-Quintana M, Yalcin A, Zavolan M, Marks D, Snyder B, Gaasterland T, Meyer J, Tuschl T. 2003. The small RNA profile during Drosophila melanogaster development. Dev Cell 5: 337-350.

Aravin A, Gaidatzis D, Pfeffer S, Lagos-Quintana M, Landgraf P, Iovino N, Morris P, Brownstein MJ, Kuramochi-Miyagawa S, Nakano T, et al. 2006. A novel class of small RNAs bind to MILI protein in mouse testes. Nature 442: 203-207.

Aravin AA, Sachidanandam R, Girard A, Fejes-Toth K, Hannon GJ. 2007. Developmentally regulated piRNA clusters implicate MILI in transposon control. Science 316: 744-747.

Arkov AL, Wang JY, Ramos A, Lehmann R. 2006. The role of Tudor domains in germline development and polar granule architecture. Development 133: 4053-4062. 
Bastock R, St Johnston D. 2008. Drosophila oogenesis. Curr Biol 18: R1082-R1087.

Bedford MT, Richard S. 2005. Arginine methylation an emerging regulator of protein function. Mol Cell 18: 263-272.

Boisvert FM, Cote J, Boulanger MC, Cleroux P, Bachand F, Autexier C, Richard S. 2002. Symmetrical dimethylarginine methylation is required for the localization of SMN in Cajal bodies and pre-mRNA splicing. J Cell Biol 159: 957-969.

Boswell RE, Mahowald AP. 1985. tudor, a gene required for assembly of the germ plasm in Drosophila melanogaster. Cell 43: 97-104.

Brennecke J, Aravin AA, Stark A, Dus M, Kellis M, Sachidanandam R, Hannon GJ. 2007. Discrete small RNA-generating loci as master regulators of transposon activity in Drosophila. Cell 128: 1089-1103.

Carmell MA, Xuan Z, Zhang MQ, Hannon GJ. 2002. The Argonaute family: Tentacles that reach into RNAi, developmental control, stem cell maintenance, and tumorigenesis. Genes \& Dev 16: 2733 2742.

Carmell MA, Girard A, van de Kant HJ, Bourc'his D, Bestor TH, de Rooij DG, Hannon GJ. 2007. MIWI2 is essential for spermatogenesis and repression of transposons in the mouse male germline. Dev Cell 12: 503-514.

Cavey M, Hijal S, Zhang X, Suter B. 2005. Drosophila valois encodes a divergent WD protein that is required for Vasa localization and Oskar protein accumulation. Development 132: 459-468.

Chuma S, Hosokawa M, Kitamura K, Kasai S, Fujioka M, Hiyoshi M, Takamune K, Noce T, Nakatsuji N. 2006. Tdrd1/Mtr-1, a tudorrelated gene, is essential for male germ-cell differentiation and nuage/germinal granule formation in mice. Proc Natl Acad Sci 103: 15894-15899.

Chuma S, Hosokawa M, Tanaka T, Nakatsuji N. 2009. Ultrastructural characterization of spermatogenesis and its evolutionary conservation in the germline: Germinal granules in mammals. Mol Cell Endocrinol 306: 17-23.

Cote J, Richard S. 2005. Tudor domains bind symmetrical dimethylated arginines. J Biol Chem 280: 28476-28483.

Cox DN, Chao A, Baker J, Chang L, Qiao D, Lin H. 1998. A novel class of evolutionarily conserved genes defined by piwi are essential for stem cell self-renewal. Genes \& Dev 12: 3715-3727.

Dansereau DA, Lasko P. 2008. The development of germline stem cells in Drosophila. Methods Mol Biol 450: 3-26.

Deng W, Lin H. 2002. miwi, a murine homolog of piwi, encodes a cytoplasmic protein essential for spermatogenesis. Dev Cell 2: 819-830.

Ephrussi A, Lehmann R. 1992. Induction of germ cell formation by oskar. Nature 358: 387-392.

Friesen WJ, Paushkin S, Wyce A, Massenet S, Pesiridis GS, Van Duyne G, Rappsilber J, Mann M, Dreyfuss G. 2001. The methylosome, a $20 \mathrm{~S}$ complex containing JBP1 and pICln, produces dimethylarginine-modified Sm proteins. Mol Cell Biol 21: 82898300.

Friesen WJ, Wyce A, Paushkin S, Abel L, Rappsilber J, Mann M, Dreyfuss G. 2002. A novel WD repeat protein component of the methylosome binds Sm proteins. J Biol Chem 277: 8243-8247.

Ghildiyal M, Zamore PD. 2009. Small silencing RNAs: An expanding universe. Nat Rev Genet 10: 94-108.

Girard A, Hannon GJ. 2008. Conserved themes in small-RNAmediated transposon control. Trends Cell Biol 18: 136-148.

Girard A, Sachidanandam R, Hannon GJ, Carmell MA. 2006. A germline-specific class of small RNAs binds mammalian Piwi proteins. Nature 442: 199-202.

Gonsalvez GB, Rajendra TK, Tian L, Matera AG. 2006. The Smprotein methyltransferase, dart5, is essential for germ-cell specification and maintenance. Curr Biol 16: 1077-1089.

Gonsalvez GB, Tian L, Ospina JK, Boisvert FM, Lamond AI, Matera AG. 2007. Two distinct arginine methyltransferases are required for biogenesis of Sm-class ribonucleoproteins. J Cell Biol 178: $733-740$.

Grivna ST, Beyret E, Wang Z, Lin H. 2006. A novel class of small RNAs in mouse spermatogenic cells. Genes \& Dev 20: 1709-1714.
Gunawardane LS, Saito K, Nishida KM, Miyoshi K, Kawamura Y, Nagami T, Siomi H, Siomi MC. 2007. A slicer-mediated mechanism for repeat-associated siRNA 5' end formation in Drosophila. Science 315: 1587-1590.

Harris AN, Macdonald PM. 2001. Aubergine encodes a Drosophila polar granule component required for pole cell formation and related to eIF2C. Development 128: 2823-2832.

Hosokawa M, Shoji M, Kitamura K, Tanaka T, Noce T, Chuma S, Nakatsuji N. 2007. Tudor-related proteins TDRD1/MTR-1, TDRD6, and TDRD7/TRAP: Domain composition, intracellular localization, and function in male germ cells in mice. Dev Biol 301: 38-52.

Houston DW, King ML. 2000. Germ plasm and molecular determinants of germ cell fate. Curr Top Dev Biol 50: 155-181.

Houwing S, Kamminga LM, Berezikov E, Cronembold D, Girard A, van den Elst H, Filippov DV, Blaser H, Raz E, Moens CB, et al. 2007. A role for Piwi and piRNAs in germ cell maintenance and transposon silencing in zebrafish. Cell 129: 69-82.

Jongens TA, Hay B, Jan LY, Jan YN. 1992. The germ cell-less gene product: A posteriorly localized component necessary for germ cell development in Drosophila. Cell 70: 569-584.

Kim VN, Han J, Siomi MC. 2009. Biogenesis of small RNAs in animals. Nat Rev Mol Cell Biol 10: 126-139.

Kirino Y, Kim N, de Planell-Saguer M, Khandros E, Chiorean S, Klein PS, Rigoutsos I, Jongens TA, Mourelatos Z. 2009. Arginine methylation of Piwi proteins catalysed by dPRMT5 is required for Ago3 and Aub stability. Nat Cell Biol 11: 652-658.

Klattenhoff C, Theurkauf W. 2008. Biogenesis and germline functions of piRNAs. Development 135: 3-9.

Krause CD, Yang ZH, Kim YS, Lee JH, Cook JR, Pestka S. 2007. Protein arginine methyltransferases: Evolution and assessment of their pharmacological and therapeutic potential. Pharmacol Ther 113: $50-87$.

Kuramochi-Miyagawa S, Kimura T, Yomogida K, Kuroiwa A, Tadokoro Y, Fujita Y, Sato M, Matsuda Y, Nakano T. 2001. Two mouse piwi-related genes: miwi and mili. Mech Dev 108: 121-133.

Kuramochi-Miyagawa S, Kimura T, Ijiri TW, Isobe T, Asada N, Fujita Y, Ikawa M, Iwai N, Okabe M, Deng W, et al. 2004. Mili, a mammalian member of piwi family gene, is essential for spermatogenesis. Development 131: 839-849.

Lau NC, Seto AG, Kim J, Kuramochi-Miyagawa S, Nakano T, Bartel DP, Kingston RE. 2006. Characterization of the piRNA complex from rat testes. Science 313: 363-367.

Li C, Vagin VV, Lee S, Xu J, Ma S, Xi H, Seitz H, Horwich MD, Syrzycka M, Honda BM, et al. 2009. Collapse of germline piRNAs in the absence of Argonaute3 reveals somatic piRNAs in flies. Cell 137: 509-521.

Lim AK, Kai T. 2007. Unique germ-line organelle, nuage, functions to repress selfish genetic elements in Drosophila melanogaster. Proc Natl Acad Sci 104: 6714-6719.

Liu X, Fortin K, Mourelatos Z. 2008. MicroRNAs: Biogenesis and molecular functions. Brain Pathol 18: 113-121.

Mahowald AP. 2001. Assembly of the Drosophila germ plasm. Int Rev Cytol 203: 187-213.

Malone CD, Hannon GJ. 2009. Small RNAs as guardians of the genome. Cell 136: 656-668.

Malone CD, Brennecke J, Dus M, Stark A, McCombie WR, Sachidanandam R, Hannon GJ. 2009. Specialized piRNA pathways act in germline and somatic tissues of the Drosophila ovary. Cell 137: 522-535.

Meister G, Eggert C, Buhler D, Brahms H, Kambach C, Fischer U. 2001. Methylation of Sm proteins by a complex containing PRMT5 and the putative U snRNP assembly factor pICln. Curr Biol 11: 1990-1994.

Miyoshi K, Tsukumo H, Nagami T, Siomi H, Siomi MC. 2005. Slicer function of Drosophila Argonautes and its involvement in RISC formation. Genes \& Dev 19: 2837-2848.

Nishida KM, Saito K, Mori T, Kawamura Y, Nagami-Okada T, Inagaki S, Siomi H, Siomi MC. 2007. Gene silencing mechanisms 


\section{Kirino et al.}

mediated by Aubergine piRNA complexes in Drosophila male gonad. RNA 13: 1911-1922.

Reuter M, Chuma S, Tanaka T, Franz T, Stark A, Pillai RS. 2009. Loss of the Mili-interacting Tudor domain-containing protein-1 activates transposons and alters the Mili-associated small RNA profile. Nat Struct Mol Biol 16: 639-646.

Ruby JG, Jan C, Player C, Axtell MJ, Lee W, Nusbaum C, Ge H, Bartel DP. 2006. Large-scale sequencing reveals 21U-RNAs and additional microRNAs and endogenous siRNAs in C. elegans. Cell 127: 1193-1207.

Saito K, Nishida KM, Mori T, Kawamura Y, Miyoshi K, Nagami T, Siomi H, Siomi MC. 2006. Specific association of Piwi with rasiRNAs derived from retrotransposon and heterochromatic regions in the Drosophila genome. Genes \& Dev 20: 2214-2222.

Savitsky M, Kwon D, Georgiev P, Kalmykova A, Gvozdev V. 2006. Telomere elongation is under the control of the RNAi-based mechanism in the Drosophila germline. Genes \& Dev 20: 345-354.

Schupbach T, Wieschaus E. 1986. Germline autonomy of maternaleffect mutations altering the embryonic body pattern of Drosoph ila. Dev Biol 113: 443-448.

Selenko P, Sprangers R, Stier G, Buhler D, Fischer U, Sattler M. 2001. SMN tudor domain structure and its interaction with the Sm proteins. Nat Struct Biol 8: 27-31.

Smith JM, Bowles J, Wilson M, Teasdale RD, Koopman P. 2004. Expression of the tudor-related gene Tdrd5 during development of the male germline in mice. Gene Expr Patterns 4: 701-705.

Strome S, Lehmann R. 2007. Germ versus soma decisions: Lessons from flies and worms. Science 316: 392-393.

Thomson T, Lasko P. 2004. Drosophila tudor is essential for polar granule assembly and pole cell specification, but not for posterior patterning. Genesis 40: 164-170.
Thomson T, Lasko P. 2005. Tudor and its domains: Germ cell formation from a Tudor perspective. Cell Res 15: 281-291.

Thomson T, Liu N, Arkov A, Lehmann R, Lasko P. 2008. Isolation of new polar granule components in Drosophila reveals P body and ER associated proteins. Mech Dev 125: 865-873.

Vagin VV, Sigova A, Li C, Seitz H, Gvozdev V, Zamore PD. 2006. A distinct small RNA pathway silences selfish genetic elements in the germline. Science 313: 320-324.

Vagin VV, Wohlschlegel J, Qu J, Jonsson Z, Huang X, Chuma S, Girard A, Sachidanandam R, Hannon GJ, Aravin AA. 2009. Proteomic analysis of murine Piwi proteins reveals a role for arginine methylation in specifying interaction with Tudor family members. Genes \& Dev 23: 1749-1762.

Vasileva A, Tiedau D, Firooznia A, Muller-Reichert T, Jessberger R. 2009. Tdrd6 is required for spermiogenesis, chromatoid body architecture, and regulation of miRNA expression. Curr Biol 19: 630-639.

Wang J, Saxe JP, Tanaka T, Chuma S, Lin H. 2009. Mili interacts with tudor domain-containing protein 1 in regulating spermatogenesis. Curr Biol 19: 640-644.

Watanabe T, Takeda A, Tsukiyama T, Mise K, Okuno T, Sasaki H, Minami N, Imai H. 2006. Identification and characterization of two novel classes of small RNAs in the mouse germline: Retrotransposon-derived siRNAs in oocytes and germline small RNAs in testes. Genes \& Dev 20: 1732-1743.

Williamson A, Lehmann R. 1996. Germ cell development in Drosophila. Annu Rev Cell Dev Biol 12: 365-391.

Zhao Q, Rank G, Tan YT, Li H, Moritz RL, Simpson RJ, Cerruti L, Curtis DJ, Patel DJ, Allis CD, et al. 2009. PRMT5-mediated methylation of histone H4R3 recruits DNMT3A, coupling histone and DNA methylation in gene silencing. Nat Struct Mol Biol 16: 304311. 

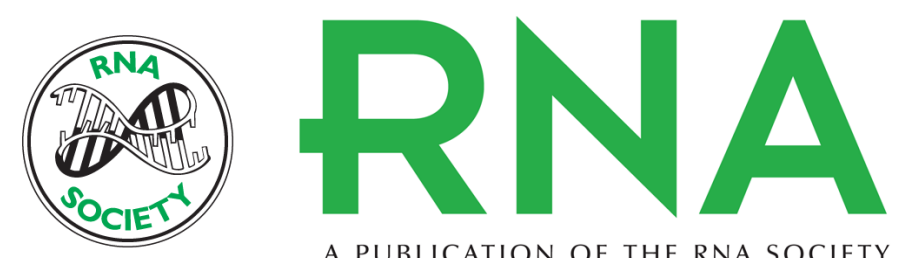

A PUBLICATION OF THE RNA SOCIETY

\section{Arginine methylation of Aubergine mediates Tudor binding and germ plasm localization}

Yohei Kirino, Anastassios Vourekas, Nabil Sayed, et al.

RNA 2010 16: 70-78 originally published online November 19, 2009

Access the most recent version at doi:10.1261/rna.1869710

\section{Supplemental http://rnajournal.cshlp.org/content/suppl/2009/11/06/rna.1869710.DC1 \\ Material}

References This article cites 69 articles, 28 of which can be accessed free at:

http://rnajournal.cshlp.org/content/16/1/70.full.html\#ref-list-1

\section{License}

Email Alerting Receive free email alerts when new articles cite this article - sign up in the box at the Service top right corner of the article or click here.

To subscribe to RNA go to:

http://rnajournal.cshlp.org/subscriptions 